Krakowskie
Studia
Międzynarodowe

J. J. Smolicz

\title{
CONSTRUCTIVE DIVERSITY IN MULTICULTURAL AUSTRALIA
}

\section{Globalisation and the Sovereignty of the Nation-State}

Under the impact of economic, political and cultural globalisation one could expect that the whole world would tend to become more and more culturally homogeneous until a convergence of cultures eventuated. Such homogenizing forces have impinged upon nation-states causing them to lose some of their traditional omnipotence and charisma. The rising significance of international organisations has eroded some of the states' powers, as has the increasing acceptance of dual citizenship and the rising tide of migratory flows across the globe.

Even a country such as Australia, which was formerly proud of its ability to control immigration inflow by carefully classifying immigrants as 'skilled', 'family reunion', 'refugees' and 'humanitarian need' cases is now in the forefront of debate on how to deal with asylum seekers who arrive without official papers by boat, by air or inside cargo containers. The 'illegal' migration flow has become a major problem, with controversial 'solutions' ranging from compulsory detention, the 'Pacific' option, and the foreshadowed excision of all islands North of the coast of Australia from the immigration zone.

The mass arrival of illegal immigrants places the state in a dilemma of balancing humanitarian concerns against the discharge of its function as regulatory authority in upholding the sovereignty of the state. As the Australian Prime Minister, John Howard (2001a: 11), has put it, "there is a concern inside the Government...that we are fast reaching a stage where we are losing... our absolute rights to decide who comes to this country." Subsequently, he asserted that it was "in the national interest that we have the power to prevent, beyond any argument, people infringing the sovereignty of this country..." (Howard, 2001b: 1). But just as the Australian Government was moving to protect its 'sovereignty' by tightening the laws governing the processing of asylum seekers, the Afghan crisis led it to re- 
spond to the appeals of the Secretary General of UN by lifting the humanitarian component of Australia's immigration program to 12,000 .

The doctrine of the absolute sovereignty of the nation-state has been dramatically undermined as a result of the events of September 11. The American doctrine on this point has been succinctly stated by William Safire (2000: p. 8) who wrote that, the emergence of terrorism as a global threat has forced nation-states to adopt a new view of sovereignty. If a governing body cannot stop terrorists who are victimizing others from its territory, then governments of the victims will reach across the borders to do the necessary stopping. [According to] George Schulz, former Secretary of State ... "we reserve, within the framework of our right to selfdefence, the right to preempt terrorist threats within a state's borders".

The weakening authority of the nation-state in the face of such crises has paradoxically generated yet another kind of force that counteract the homogenising effects of globalisation. As control slips out of its grasp, the state faces the rising demands of its local, regional and various other minority groups which are gaining confidence and demanding their 'place in the sun'. We are witnessing round the world a renaissance, a resurgence, of a great variety of cultural diversities, including that of ethnicity. While political boundaries are tending to become more permeable, especially in places like Western Europe (Dogan, 2000), cultural boundaries are becoming accentuated within countries (Davies, 1997; Huntington, 1996). In this context, it is manifest that the cultural and political boundaries between states do not necessarily coincide and that very few countries in the world today are culturally homogeneous: most are multi-ethnic.

\section{Ethnic Diversity and the Nation-State}

Different countries have responded in different ways to this ethnic challenge. Not every state recognises its growing cultural and ethnic diversity. Some have for long tried to deny its existence, as in the case of the Turks. Some hoped that their plurality was only temporary, as in the case of Germans. In fact, Germany has for long provided an example of a country where membership of the nation has been based traditionally on the assumption of common descent, and, therefore until very recently, people of non-German ancestry had no entry to the nation, and hence, no ready access to citizenship of the state, which has been virtually 'closed' to those who did not satisfy the German origin criterion. There are countries in Asia which share a similar belief in the ideal of monocultural nation-state based on common descent.

In other countries multi-ethnicity has lead to territorial separatism, including the building of walls perceived as the only alternative to terrorists attacks, insurgency and warfare. In still other cases there has been no separation, but every effort has been made to assimilate the minorities out of existence. This policy continues to mark the French state's approach to its historic regions, as well as to its new immigrant groups. In contrast to the Germans, the French nation-state is 'open', in 
the sense that it has been possible to gain entry to the French state through naturalisation, as many North Africans have already shown. Once one enters the French state, one is assumed to have become part of the French nation, and hence required to assimilate totally to French culture. The official French assumption is that admission to French citizenship should virtually automatically bring with it the obliteration of the new citizen's original culture, even if does not necessarily translate into his/her social acceptance or job market equality. France is by no means the only country which believes in the 'republican ideal' that equality can best be achieved in a culturally homogenous society in which all cultural alternatives have been all but eliminated. There are Asian countries which also share similar beliefs, without necessarily being republics.

As the American political scientist, Safran, (1995: 2) has asserted, in the world today, most states "cannot cope 'neatly' with ethnic reality short of disposing of it by expulsion, extermination, ghettoisation, forceable assimilation and other methods now widely considered to be oppresive, undemocratic, or at least 'inelegant"'. Safran maintains that there is a consensus about the existence of ethnic pluralist dilemmas and the danger which they may pose to the stability of the state - "but there is consensus about little else". Against this background, Australia has gradually evolved into a society that espouses its own special brand of multiculturalism. The present day Australian nation-state is very different from both its 'closed', descent-based and 'open', yet assimilative, counterparts. When viewed in this context, the controversy surrounding the current procedures adopted towards the 'illegal immigrants' should not be allowed to obscure the many positive and successful features of the Australian multicultural model.

\section{Australia and Assimilation}

As it celebrates the centenary of its federation, Australia finds itself a great distance from the image of the 'founding fathers' of the nation who drafted its constitution in 1901. The ideology of the newly emerging state was somewhat like that of Germany, in the assumption of its homogenous British character. In fact, 'real' Australians regarded themselves as some kind of regional Britons. A former Prime Minister and one of the founders of Australian Federation, Alfred Deakin, was described by Paul Kelly (1999) in the "Great Australians" series as "having correctly grasped the character of the new nation as that of Australian-Britons".

The assumed purity of the ancestral stock was preserved (not always successfully) by a discriminatory migration policy. The Aboriginal people, who were basically "out of sight, out of mind", were deemed to be disappearing or assimilating, partly through the policy of removing children of mixed descent. Thus, while in 1788, the year of European settlement, Aborigines constituted $100 \%$ of the population, this proportion declined rapidly to $13 \%$ in 1861 , and down to $0.8 \%$ in 1947. This decline was eventually arrested, with the numbers stabilizing at $1 \%$ by 1981 , and rising (through increased identification, as well as natural growth) to 
$1.5 \%$ by 1986 and $2 \%$ in 1996 (Price, 1989: 62; Hugo, 2001: 134, 197) and $2.3 \%$ according to the most recent census estimates.

After the Second World War came the massive immigration of Eastern Europeans, such as Ukrainians, Poles, Lithuanians, Latvians and Estonians, then Northern Europeans, mainly Dutch and Germans, and later the immigrants from Southern Europe, followed by Lebanese and Vietnamese, South Americans, and still later by Bosnians and Timorese and many other groups. Under the impact of such an inflow of diverse peoples, it became impossible to regard the Australian population as originating solely from British stock. While at the end of World War II, only $10 \%$ of the population were born overseas (mostly in Britain), by 1999 , $24 \%$ were overseas born. And the composition of the new arrivals also altered dramatically. While in $1947,81 \%$ of the settlers came from English speaking countries, by 1999 only $39 \%$ came from this source. During the 1960's Britain still supplied $51 \%$ of the settlers, with others coming mainly from Greece, Italy, Yugoslavia, Germany and Malta. By 1990's no more than 12\% came from Britain itself, with the other main source countries being New Zealand, China (including Hong Kong), Vietnam, Philippines, South Africa and the countries of former Yugoslavia. The 'migrant' nature of the Australian population ("the greatest migrant nation in the world" according to former Prime Minister Robert Hawke) is also shown by the fact that as many as $27 \%$ of persons born in Australia had at least one parent born overseas, so that, when taken together, these first and second generation migrant Australians now account for one half of the population (51\%) (Trewin, 2001: 153).

Initially, this multitude of peoples were expected to conform to the country's assimilation policy. If all the people could not be of British stock, then they should at least behave like British-Australians. This supposition was built on the idea that all cultures, other than British, were to be abandoned. People of other backgrounds would have their former cultures thoroughly washed out of them. Such cultural assimilation did not necessarily herald structural assimilation (either at primary or secondary level), since the individual's loss of native culture did not guarantee social or occupational acceptance; certainly not in the case of Aboriginal people, and often not of other "New Australians" either.

The policy of assimilation did not prove a great success. Some people did not wish to assimilate, and clung tenaciously to their cultures and languages. Others could not assimilate because they were unable to 'disappear' and sink into oblivion within the 'mainstream'. They possessed various physical, linguistic and cultural markers that prevented their total absorption. The most sustained effort made to assimilate these 'cultural others' was through their children's schooling. The school became the agency of assimilation by excluding from the curriculum all material which did not conform to Anglo-conformist norms (the assumed 'normality' of this process was still so strongly entrenched that my use of this term in an article entitled "Is the Australian School an Assimilation Agency?", delivered at the University of Western Australia in January 1970 and first published in 1971, drew a lot of surprise and criticism at the time). The assimilation process was carried further 
through the devaluation of other cultures and languages. The school not only chose to withhold any information about Polish, Greek or Italian or Chinese cultures but was often derogatory towards the teaching of those cultures and languages which the children received from 'ethnic schools' run by the immigrant communities out of school hours, and from their own meagre resources.

There is an accumulation of research data which show the difficulties experienced by 'migrant children' as they tried to balance out their parents' emphasis on maintaining the language and culture of the 'home' country and the school's policy of uncompromising enforcement of the mainstream Anglo-Australian ways (Clyne, 1991; Smolicz, 1999). Although many of the cultural groups began to shrink under the impact of the assimilationist pressures (Clyne and Kipp, 1997), there was also a growing resistance to assimilation and refusal to disappear into the Anglo-dominated mainstream (Smolicz and Secombe, 1989).

\section{Emergence of Australian Multiculturalism}

In the era of assimilation, Australian policy resembled that of present day France, in that it upheld the principles of a political democracy for all those granted permanent residence. The new arrivals were encouraged to apply for citizenship, and gained civic equity by becoming part of the electorate in a parliamentary democracy. But there was no cultural equity. This began to change over the 1970 s with the gradual adoption of the policy of multiculturalism (Smolicz, 1997). These changes were precipitated by the 1967 referendum which gave the Aboriginal population full civic rights, and brought the Aboriginal issue onto the agenda. Multiculturalism arrived through the work of the Fraser government, following its initial advocacy by Grassby in the Whitlam government. The arrival, in 1972, of substantial numbers of Asian immigrants, mainly Vietnamese, finally broke the White Australia Policy, the barrier that hindered the full implementation of multicultural policy in Australia.

The Australian conceptualization of multiculturalism has assumed the existence of an over-arching framework of shared values within which different cultures co-existed and interacted with one another. The various ethnic groups were permitted, even encouraged, to activate their own core cultural values, provided they were within the framework of shared values, such as political democracy, rule of law, market economy and English as a shared language.

Debate still persists, however, about the degree of change that the framework can sustain. Interpretations have varied according to the degree of multiculturalism that the people concerned have been prepared to accept. Some have perceived the shared cultural framework to be essentially dynamic in its capacity to adjust to existing, as well as future, complexities in the population. They have pointed to the fact that the framework has already proved its flexibility through the belated political incorporation of Aboriginal-Australians, and the abolition of the White Australian Policy, sealed by the acceptance of the Vietnamese refugees (Jupp, 2001), 
even if much remains to be achieved in the sphere of 'reconciliation' between the descendants of immigrants and the indigenous population. 'Multicultural sceptics', afraid of fragmentation, have argued for a much more limited notion of plurality and have preferred the framework to be grounded almost totally in Anglo-Celtic core values (Bullivant, 1981; Blainey, 1984). Minority cultures were then expected to contribute only peripherally, chiefly in relation to food and the celebration of colorful customs and festivals. In spite of such doubts, the multicultural model has been sustained and officially affirmed by formal resolutions passed in the Houses of Parliament and by statements of the former Governor-General of Australia (Deane, 1997) who stated:

Australia's multiculturalism sustains the nation. It both protects and promotes respect and tolerance for the backgrounds of all Australians - for people who came from Britain as much as those whose origins were in other parts of the world.

\section{Australian Cultural Diversity}

In its current form, multiculturalism recognises the reality of cultural differences, exemplified by the fact that Australians are not all of one ancestry or all of the same religion. While people of British descent are still in a clear majority, there is a growing recognition of the presence of the indigenous inhabitants and the increasing proportion of Australians of non-British, and particularly Asian backgrounds.

Charles Price (1989: 62) has calculated the 'ethnic strength' of Australian population according to descent or ancestry. The overall proportion of British descent has declined from $90 \%$ in 1947 to $75 \%$ in 1987 and $70 \%$ in 1999 (approximately $45 \%$ English, 15\% Irish and under $10 \%$ Scottish, with smaller proportions of Welsh and Cornish). At the same time the proportion of other Europeans went up from $7.5 \%$ in 1947 to over $18 \%$ in 1999 , while 'Asian' increased from $0.3 \%$ to $6.4 \%$, with an additional 2.5\% of West Asian (Middle Eastern) origin (Hugo, 2001: 181). The Asian ethnic strength has grown under the impact of an increased number of Asian-born new arrivals which has fluctuated markedly, peaking over 1988$1989(55,700)$ and $1990-1991(60,900)$. In 1998-1999, 21,800 settlers (26\% of the total) arrived from Asia. [It is of interest to note that during the same time the number of long-term visitor arrivals from Asia has also been increasing, with some $72 \%$ of them being students. Their number reached 53,500 in 1998 , or $45 \%$ of the total arrivals, nine times as high as in 1978-79 and three times as high as in 19881989 (Trewin, 2001:151).]

The change in ancestry is paralleled by a greater diversification of Australians' religious beliefs, with the adherents of Anglican Church falling from $40 \%$ of the proportion in 1901 to $22 \%$ in 1996 , while Catholics increased their proportion from $23 \%$ to $27 \%$. Over the last twenty years there has also been a growth of nonChristian religions (3.5\% in 1996), with Hinduism increasing by $55 \%$, Buddhism by $43 \%$ and Islam by $36 \%$. The most remarkable, however, has been the growth of 
those who stated that they had no religion (from $0.4 \%$ in 1901 to $17 \%$ in 1996 ) or those who indicated no affiliation with any religion (an increase from $2 \%$ to $9 \%$ in the same period). Overall almost one quarter of the current population are not affiliated with any religion, showing the growing secularisation and diversification of the Australian people.

Diversity of ancestry and religion is matched by Australia's linguistic pluralism. English became dominant colonial language from the time of European settlement in 1788, when it was implanted upon an Aboriginal society which was itself multilingual. It has been estimated that before European settlement there existed some 250 Australian indigenous languages, as well as some 600 dialects. By 1900 , about 100,000 Indigenous people still spoke their own language, but by 1996 , there remained no more than 44,000 people ( $14 \%$ of the total Aboriginal population) who spoke either an Australian indigenous language or an Australian creole (a language derived from pidgin English). Multicultural policies have altered the climate of values in Australia, making it much more positive to preserving indigenous languages, with 48 of them listed in the 1996 census. The downward slide in the use of these 'Languages of Australia' (a term currently preferred by the Indigenous Australians) has not been arrested, however, so that even one of the most widely spoken language, Arrente, had no more than 3,500 speakers in 1996.

While no data on language use were collected until 1976, information on 'race and nationality' suggests that Chinese languages and German were the most commonly spoken immigrant languages other than English before federation in 1901. A number of private Lutheran schools, with German as the language of instruction, were established over the 19th century, but these were either closed down or obliged to change to English at the time of World War I in 1915 (Selleck, 1980; Clyne, 1985). There was rapid expansion in the number of languages spoken in Australia following the massive European and Asian migration after World War II. It was not until end of 1970's, however, that most state parliaments repealed laws that forbade the use of languages other than English as medium of instruction in non-government schools. In 1996 about 2.5 million people (16\% of the population five years and over) spoke a language other than English at home (an increase from $14 \%$ in 1986). In all, over 200 languages were spoken with the leading five, Italian, Greek, Chinese, Arabic and Vietnamese, each having over 100,000 speakers. These "languages other than English" (LOTE), are mainly spoken by first generation Australians (ie those born overseas) (74\%), while $26 \%$ are Australian-born speakers, showing a tendency to maintain LOTE over more than one generation.

Acceptance of multiculturalism as the official policy has enabled Australia to take the lead and become one of the first countries to launch a National Policy on Languages. Recognizing that different ethnic identities are often rooted in their specific languages, the Lo Bianco Report (1987) proposed that the education system should provide for students to learn English and at least one other language, which could be either a minority ethnic language, often labelled as "community language other than English", or a foreign language. Under this policy, students at school would be encouraged, and in some states even required, to study a language 
other than English (in South Australia up to year 10 from 2007). Minority young people were thus being given the opportunity to participate in the mainstream of Australian life, while acquiring literacy in other tongues, some of which they already spoke in their homes, but which they could also use in businesses in Australia and with trading partners overseas. This approach has given rise to a more positive image of Australian bilinguals in the role of cultural bridges that can link different communities within Australia with those overseas, thus conferring important economic as well as socio-cultural benefits upon the country. Such possibilities have put paid to objections about the continued existence of languages other than English on the ground that they would supplant English. In fact, research evidence points to the fact that English has been accepted unquestioningly as the shared language for all Australians, with over $80 \%$ of LOTE speakers claiming to know English "well" or "very well" in the 1996 census (Trewin, 2001:165).

\section{Constructive Diversity in a Multicultural Nation-State}

By rejecting both the German- and French-type monistic nation-state models, Australia has embraced a level constructive diversity, involving political and cultural co-existence, whereby people are accepted from different backgrounds on their own cultural terms. One of the indications of the sustainability of Australian multiculturalism has been the extent to which Australian citizens can at present retain aspects of their non-British cultural heritage and descent and be accepted as fully Australian, i.e, as authentic members of the Australian nation and state.

One issue which has been causing some concern is the fact that there are certain British 'markers' which have been almost invariably accepted as simply 'normal', whereas markers from other origins have tended to be used as labels that single out and differentiate minorities. An obvious one is that of physical appearance. Apprehension has long persisted as to the danger that Australians of Aboriginal or Asian origin, for example, could be subject to racial labelling or even discrimination.

There is also the danger of other forms of discrimination which are not based on physical appearance but may exist on the grounds of difference in culture, language, religion, family structure, the clothes worn, or the food eaten. In the postworld war II period incidents were reported concerning, for example, the difficulties experienced at school by children of Southern or Eastern European background on account of such apparently innocuous items as the "smelly" lunches which they brought to school. A number of adults have recalled how, as children, they threw their lunches in the bin, despite their mother's efforts to give the 'best' their home cultures taught them. This was in response to other children making them feel ashamed of being different. Although those are stories from the past assimilationist era, there still lingers a degree of sensitivity about 'labelling' on the grounds of culture, which can be referred to as cultural racism, ethnicism or linguism. 
The danger of such possible pitfalls has become more widely understood in Australia, with the education system devising programs that demonstrate to the students that, in order to survive and develop as a nation along multicultural lines, the country needs more than the common political machinery of the democratic state. It requires also the cultivation and sustained growth of cultural values that extend beyond political structures and not only reflect the majority group's values, but also take account of the minority groups' aspirations to maintain their cultural identity, as exemplified what we have termed their core values (Smolicz, 1981; Smolicz\&Secombe, 1989; Smolicz, Hudson \& Secombe, 1998).

Different ethnic groups exhibit a diverse range of values which they regard as essential for their continuity and integrity. Because of their strong identification with their native tongue, some groups can be viewed as particularly languagecentered, since the loss of their language endangers their cultural vitality. As a consequence, such groups can become culturally 'residualized' and lose their powers of creativity and development. Polish, Greek, French and Baltic groups can be regarded as belonging to this category. Others are more clearly linked to religion, as in the particular case of Malays' allegiance to Islam, so that its loss endangers the individuals' membership of the group concerned. Other cultures are centered around family or clan structure and the concern to perpetuate the group's descent. Some groups are fortunate in having a multiple set of core values, for example, an ethno-specific language, religion and a supporting collectivist family structure to maintain their identity (Smolicz, Secombe and Hudson, 2001).

The recognition of the significance of cultural core values for various groups does not imply a tendency to promote their separatism within the state. On the contrary, the maintenance of such values in a multicultural Australian setting is built upon the principle of constructive diversity that is based upon cultural interaction among the groups, involving an exchange process, rather than simply one way traffic favouring one group to the detriment of another. Such a dynamic process, which proceeds through a degree of cultural synthesis, diffusion and coexistence, takes place within the framework of the shared overarching values to which all groups are entitled to make their particular contribution. Minority groups have then no need to fear the loss of their essential cultural elements. In this way one of insidious forces that could drive them toward separatism is being eliminated, since groups concerned cease to have any inclination towards isolationism and fragmentation.

\section{Australian Multiculturalism and the Becalming of Ancient Group Animosities}

The mutual confidence in a sustainable multicultural structure has lead to increased trust and cooperation not only between the majority group and the minorities but also the minority groups themselves, some of whom derive from countries where they existed in a state of conflict, tension and mutual hostility. In a number of instances multicultural Australia has succeeded in removing the "sting" from among 
peoples and their descendents who in their original homelands were known to dwell in a state of mutual animosity or even open conflict. Many members of these groups have reached a point of accommodation within the Australian multicultural context. A number of the mutually antagonistic neighbouring peoples in Europe, Asia and Africa, such as Poles and Germans; Greeks and Slavonic-speaking Macedonians; Vietnamese and Chinese; Eritreans and Ethiopians have succeeded in interacting within Australian ethnic and multicultural councils and federations (such as the Federation of Ethnic Communities Councils (FECCA)) and to cooperate across ethnic divisions. One of the factors working for this acomodation is the security, respect and equality provided to all groups within the framework of shared Australian values, sharpened by the common aim to lobby the State and Federal government to provide adequate support for their particular language and culture maintenance and to insure equity of access to the all-Australians institutions and structures.

One of the areas being researched is the Horn of Africa and the people who derive their origins from Ethiopia, Eritrea, Somalia, Sudan and Dijibouti - countries which have been politically turbulent, economically depressed and environmentally devastated. (Debela, 1996). The peoples of these 'disturbed' countries are distinctive in their diversity and include ethnic groups that transcend national boundaries, generating complex clan/ethnic affiliations, as well as differences in languages spoken, religious beliefs and political views. Refugees, settlers on special humanitarian grounds and, to a much smaller extent, immigrants from this area have formed a highly visible community in Australia. The complexity of the interactions of these groups of settlers in South Australia, and their relationships with the wider Australian community have formed a fascinating study indicative of the process of acculturation and adjustment within the orbit of the Horn of Africa community as a whole. Of special interest has been the nature of the apparent social integration and cohesion that have developed in Australia within the mosaic of national, ethnic, clan and linguistic groupings from the Horn - and all these in spite of decades of bloody and continuing interethnic violence in Africa. The degree to which many of these groups have succeeded in putting aside their historical enmities, overcome their differences and cooperate to rebuild their life in the new country, testifies to the vitality of the phenomenon of multicultural Australia and its ability to moderate and heal former enmities.

This phenomenon of inter-group cohesion generated in Australia, constitutes still largely undocumented major theme of the Australia migration story - a story of success currently overshadowed by the unfortunate experiences generated by the "the illegal boat migration" incidents. While Australia successes in integrating migrants with the majority group and with each other undoubtedly owes much to the relative economic wealth and prosperity of the country, there is no doubt that multicultural policy approach that stresses respect for the cultural values of newcomers and the need for social and cultural equality has contributed greatly to the emerging social consensus and political stability of the country as a whole. 
From a comparative perspective, the achievement of Australia can be judged best on the extent to which it has been able to engage in a process of reshaping itself by attempting to recognise its own plurality and by demonstrating that tolerance of diversity and gradually emerging pluralist policies in languages and culture education are a better guarantee of stability than enforced rapid assimilation to one dominant language and culture.

An idealized multicultural model, to which Australia aspires, is free from the divisions that are most difficult to bridge, as when one particular religion is made mandatory or when racial or ancestral characteristics are regarded as exclusion markers that set the limits of nationhood. In order to reinforce these multicultural goals, Australia has established an array of anti-discriminatory State and Federal legislation, with an active role assigned to the ombudsmen. Such structures have been augmented by sustained educational efforts to propagate school curriculum which condemned all forms of racism, whether based upon appearance, language, customs or religion. Australian states have developed programs of "Countering Racism through Developing Cultural Understanding", which demonstrate that while it will never be possible for all Australians to look alike, practise the same religion, live in the same type of family household or relish the same kind of food, all these practices need to be understood and accepted as compatible with the Australian nationhood and requiring the same respect and protection. The affirmation of this principle by successive governments is reassuring - always with the proviso that the cultural practices concerned are carried out within the Australian constitution and legal system and within the dynamic overarching framework of shared values.

\section{Multiculturalism and Human Rights}

Questions have been raised about the possible existence of "essential contradictions" within multiculturalism, and whether Australia has succeeded in resolving them within its multicultural model. The difficulties in reconciling cultural diversity with good governance might, for example, arise out of the paradox that a democratic Australia generates a respect for cultural diversity coupled with the policies that assume the universality of certain fundamental values. The balance between these two facets of contemporary Australian society must take into account differences in ethnicity, religion and other aspects of culture which co-exist within its legal and constitutional structures which are based on belief in the universality and indivisibility of 'common' human rights. It is a dilemma, which extends well beyond the borders of Australia, up to the seeming contradiction between the universality of individual human rights and the diversity of cultures and civilizations.

In the context of Australia, Justice Michael Kirby (1998) of the High Court has helped towards the resolution of some these issues by insisting on the interdependence of political, economic, social, cultural and linguistic rights. He has 
pointed out that Western perceptions of human rights have changed over time. For example, the notion of political suffrage in Western countries did not extend to women or to some ethnic and racial minorities until quite recently. What is more, many minority groups throughout the world, particularly those of indigenous origin or alternative sexuality, are still denied access to the full range of human rights. Kirby concluded that in the matter of human rights, "the Voyage of Discovery, which the United Nations' Universal Declaration of Human Rights (1950) initiated is far from complete".

The fact that, since 1967, all citizens, including the Indigenous inhabitants, can exercise full political and legal rights as Australians, does not, however, on its own, make adequate recompense for the past, nor provide any acknowledgement of the Aboriginal people's unique cultural heritage. Only over recent years, and in the climate of world-wide concern with indigenous rights on the part of international organisations, has Australia become actively involved in the process of 'Reconciliation' with Aboriginal Australians. There has been a rising consciousness of the need to make amends for the past appropriation of the land and destruction of so many aspects of indigenous culture.

For many Aboriginal people, assimilation to the point of vanishing into the 'mainstream' has not been a practical proposition. What is more, some of them did not wish to 'vanish'. Their lack of gratitude to the assimilation offer, which was extended after years of separation and domination, astounded many Australians, as many Aboriginal people persisted in their quest for Australianness in their own particular Aboriginal way, including the activation of their languages and cultural heritage, which directly involved their ancestral land.

The High Court rulings that legally dismantled the notion of 'terra nullius', or the view of Australia as an 'empty' land that Europeans could occupy and use at will; the refusal to extinguish Aboriginal rights to their ancestral land which was currently leased to pastoralists; the setting up of the Aboriginal and Torres Strait Islander Commission enabling Aboriginal Australians to have a voice in their own affairs; and finally the setting up of Council for Aboriginal Reconciliation, have opened the way to achieving the sought for Reconciliation. Central to this process has been the recognition that human rights for Aboriginal Australians cannot be achieved without full appreciation of indigenous cultural heritage and tradition. In this sense, Reconciliation is intimately linked with the UN Universal Declaration of Human Rights.

On the occasion of 50th anniversary of the Universal Declaration, Justice Kirby spoke of the need for its update, without diminishing the universality of fundamental human rights that it enshrined. When applied to Australia, these are embodied in parliamentary democracy and equal civic rights for all citizens. The acknowledgement by the Asia-Pacific NGO for World Conference on Human Rights (1992) that "universal human rights standards are rooted in many cultures", makes it possible to develop a model of Human Rights for Australia which links both Multiculturalism and Reconciliation. In the Tree Model (see diagram 1), the tree trunk represents the civic and political rights portrayed as the indivisible and 
universal aspects of Australian democracy. The branches of the 'tree' illustrate the different cultural rights of all the diverse groups that make up Australian society, including Aboriginal Australians. The model shows the linkage between respect for religious human rights with those involving the rights to land because of the Aboriginal spirituality that connects the two. Similarly, it demonstrates how respect for the family collectivism in Aboriginal life highlights the grief currently being expressed by the elderly people who were victims of the policy of removing children of European fathers from their Aboriginal mothers and transferring them to orphanages or foster families.

The successful outcome of the Reconciliation process with Indigenous Australians through the recognition of their human rights, shared with all Australians in their civic and political aspects, while permitting diversity in their cultural manifestations, has implication for Australian multiculturalism as it applies to all groups. The model demonstrates particularly well the need for flexibility and dynamic nature of the overarching framework if it is to accomodate the needs of all Australians, including the Aboriginal people. Their previous exclusion has impoverished the nation. Their current inclusion enriches it and broadens the dimensions of permitted particularities within the framework of universal human rights.

The same type of framework could be adopted by other culturally plural countries as they strive to harmonise their cultural diversity with a stable and resilient nation-state that adheres to the principles of universal human rights. As the 'Tree Model' indicates, some rights are indeed indispensable in a democratic state. These include civic, political and cultural rights, as indicated by the 'trunk' in the 'tree diagram'. The cultural rights, however need not conform to a single pattern, with the 'crown' of the tree assuming different configurations, depending on the cultural traditions of the groups that make the nation and their members' current aspirations. The ultimate success of the Australian multicultural achievement lies in the fact that the various cultural branches can grow freely, while ensuring that no single one can crowd out the others and that their development occurs harmoniously within an unifying and flexible framework underpinned by the UN Universal Declaration of Human Rights.

\section{References}

Bullivant B. M. (1981), The Pluralist Dilemma in Education, Sydney.

Clyne M. (1985), Multilingual Melbourne Nineteenth Century Style, "Journal of Australian Studies", Vol. 17, pp. 65-81.

Clyne M. (1991), Community Languages: The Australian Experience, Cambridge. Clyne M., Kipp S. (1997), Trends and changes in home and language shift in Australia, "Journal of Multilingual and Multicultural Development" vol. 18, pp. 451-473.

Davies N. (1997), West best, east beast, "Oxford Today", vol. 9, no. 2, pp. 28-31.

Deane W. (sir) (1997), Multiculturalism our way, "Multicultural Life" vol. 2, p. 3. 
Debela N. W. (1996), Minority Language Education with Special Reference to the Cultural Adaptation of the Ethiopian Community in South Australia. Ph.D. Thesis, Graduate School of Education, University of Adelaide.

Dogan M. (2000), Nationalism in Europe: Decline in the West, revival in the East, "Societies, Corporations and the Nation State. The Annals of the International Institute of Sociology, New Series", eds. E. K. Scheuch and D. Sciulli, vol. 7, pp. 181-200.

Howard J. (2001a), quoted in P. Kelly, In "First Step: a Deal with Indonesia", "The Australian" (August 29th), p. 11.

Howard J. (2001b), quoted by D. Shanahan, Howard: this Bill is Necessary to Protect our National Interest, "The Australian" (August 30th), p. 1.

Hugo G. (2001), A Century of Population Change in Australia, [in:] 2001 Year Book Australia, ed. D. Trewin, Canberra, Australian Bureau of Statistics, pp. 169-210.

Huntington S. (1996), The Clash of Civilizations and the Remaking of World Order, New York.

Jupp J. (2001), The Australian People: an Encyclopedia of the Nation, its People and their Origins, Cambridge.

Kirby M. (Justice) (1998), The Universal Declaration for Human Rights: Fifty Years On, Sydney.

Lo Bianco (1987), Report to Commonwealth Department of Education: National Policy on Languages, Canberra.

Price C. A. (1989), Ethnic Groups in Australia, Canberra.

Safire W. (2002), Anti-terrorism v. Sovereignty, "International Herald Tribune" (May 31), p. 8.

Safran W. (1995), Nations, ethnic Groups, states and Politics: A preface and an agenda, "Nationalism and Ethnic Politics" No. 1 (1), p. 1-10.

Selleck R. J. W. (1980), The trouble with my looking glass: a study of the attitude to Australians to Germans during the Great War, "Journal of Australian Studies", vol. 6, pp. 1-25.

Smolicz J. J. (1971), Is the Australian school an assimilationist agency?, "Education News" vol. 13, No. 4, pp. 4-8.

Smolicz J. J. (1981), Core values and cultural identity, "Ethnic and Racial Studies: an International Journal of Ethnic, Cultural and Race Relations" vol. 4, No. 1, pp. $75-90$.

Smolicz J. J. (1997), Australia: From Migrant Country to Multicultural Nation, "International Migration Review" vol. 31 (1), p. 164-186.

Smolicz J. J. (1998), Globalism, Nation-State and Local Cultures, "Political Crossroads" vol. 6, no. 1 and 2, pp. 111-128.

Smolicz J. J., Secombe M. J., Zajda J. (1999), J. J. Smolicz on Education and Culture, Melbourne.

Smolicz J. J., Secombe M. J. (1989), Types of language activation in an ethnically plural society, [in:] Status and Function of Languages and Language Varieties, ed. U. Ammon, Berlin-New York, pp. 478-514. 
Smolicz J. J., Hudson D. M., Secombe M. J. (1998), Border crossing in 'Multicultural Australia": A study of cultural valence, "Journal of Multilingual and Multicultural Development" vol. 19, p. 318.

Smolicz J. J., Hudson D. M., Secombe M. J. (2001), Family Collectivism and Minority Languages as Core Values of Culture Among Ethnic Groups in Australia, "Journal of Multilingual and Multicultural Development" vol. 22, No. 2, pp. 152-172.

Trewin D. (2001), 2001 Year Book Australia, No. 83, Canberra, Australian Bureau of Statistics. 